- Original Article

\title{
Efficacy of Vitamin C Supplements in Prevention of Cancer: A Meta-Analysis of Randomized Controlled Trials
}

\author{
Bobae Lee ${ }^{1,2,+}$, Seung-Won Oh ${ }^{3,+}$, Seung-Kwon Myung ${ }^{4,5, *}$ \\ ${ }^{1}$ Huntington University, Huntington, USA \\ ${ }^{2}$ Loma Linda University School of Medicine, Loma Linda, CA, USA (Present) \\ ${ }^{3}$ Department of Family Medicine, Healthcare System Gangnam Center, Seoul National University Hospital, Seoul, Korea \\ ${ }^{4}$ Department of Cancer Control and Policy, Graduate School of Cancer Science and Policy, Goyang, Korea \\ ${ }^{5}$ Department of Family Medicine and Center for Cancer Prevention and Detection, National Cancer Center, Goyang, Korea
}

Background: Previous randomized controlled trials (RCTs) have reported inconsistent findings regarding the association between vitamin $\mathrm{C}$ supplementation and the risk of cancer.

Methods: We performed a meta-analysis of RCTs to investigate the efficacy of vitamin C supplements for prevention of cancer. We searched the PubMed, EMBASE, and Cochrane Library databases in November 2014 using common keywords related to vitamin $C$ supplements and cancer.

Results: Among 785 articles, a total of seven trials were identified, which included 62,619 participants; 31,326 and 31,293 were randomized to vitamin C supplementation and control or placebo groups, respectively, which were included in the final analysis. A fixed-effects meta-analysis of all seven RCTs revealed no significant association between vitamin C supplementation and cancer (relative risk, 1.00; 95\% confidence intervals, 0.95-1.05). Similarly, subgroup meta-analysis by dose of vitamin $\mathrm{C}$ administered singly or in combination with other supplements, follow-up period, methodological quality, cancer mortality, gender, smoking status, country, and type of cancer also showed no efficacy of vitamin C supplementation for cancer prevention.

Conclusion: This meta-analysis shows that there is no evidence to support the use of vitamin C supplements for prevention of cancer.

Keywords: Vitamin C; Ascorbic Acid; Cancer; Randomized Controlled Trials; Meta-Analysis

Received: June 16, 2015, Revised: September 2, 2015, Accepted: September 4, 2015

*Corresponding Author: Seung-Kwon Myung Tel: +82-31-920-0479, Fax: +82-31-920-2606, E-mail: msk@ncc.re.kr

'These authors contributed equally to this work. 


\section{INTRODUCTION}

Previous animal and in vitro studies have indicated that free radicals such as reactive oxygen species (ROS) can cause cellular damage and lead to cancer by altering cellular regulatory pathways. ${ }^{1,2)}$ Vitamin $C$ has been considered an antioxidant that can prevent ROS-induced cellular damage. ${ }^{3,4)}$ However, the efficacy of vitamin C supplements for prevention of cancer has been controversial for decades.

In 1976, a possible therapeutic effect of high-dose vitamin C supplementation in 100 patients with advanced cancer was reported in a non-randomized clinical trial by Cameron and Pauling, ${ }^{5,6)}$ compared to a control group of 1,000 untreated and matched patients. However, two subsequent randomized placebocontrolled trials (RCTs) by Creagan et al. ${ }^{7)}$ and Moertel et al. ${ }^{8)}$ in 1979 and 1985 reported no beneficial effect of high-dose vitamin $C$ therapy in patients with advanced cancer.

Since then, several RCTs have shown inconsistent findings regarding the effects of vitamin $\mathrm{C}$ supplementation on the risk of cancer. In 2006, a systematic review of four RCTs indicated that vitamin $\mathrm{C}$ supplements did not increase survival in cancer patients. ${ }^{9}$ Similarly, a meta-analysis of several RCTs published in 2008 reported that vitamin C supplementation given singly or in combination with other antioxidant supplements had no effect on the prevention of gastrointestinal cancers. ${ }^{10)}$ Additionally, a meta-analysis by Jiang et al. ${ }^{11)}$ indicated that vitamin C supplementation had no significant effect on prevention of prostate cancer. Although additional large RCTs have been published, no comprehensive meta-analysis on this issue has been reported so far.

The aim of this study was to perform a meta-analysis of RCTs in order to assess the efficacy of vitamin C supplements for cancer prevention. Subgroup meta-analyses were also performed by vitamin C supplement dose, follow-up period, methodological quality, outcome, funding source, gender, smoking status, country, and type of cancer.

\section{METHODS}

\section{Data Search}

We searched the PubMed, EMBASE, and Cochrane Library databases in November 2014, using keywords related to the efficacy of vitamin C supplements for prevention of cancer. The keywords were 'vitamin C' or 'ascorbic acid,' 'cancer', and 'randomized controlled trials.' The bibliographies of relevant articles were also searched. We included only RCTs that both reported the efficacy of vitamin C supplementation on cancer prevention and compared an intervention group with a control group. The main outcome measures included cancer incidence and mortality. We did not restrict the language of publication.

\section{Study Selection and Data Acquisition}

Two authors (BL and SKM) independently assessed the eligibility of all trials identified from the databases and bibliographies. Disagreements on study eligibility were resolved by consensus or through consultation with the other author (SWO). From the studies selected for the final analysis, we retrieved the study name (with first author and year of publication), country, study design, duration of supplementation (in years), pharmaceutical industry funding, participants (number and underlying conditions), contents of intervention and control, type of cancer, and the number of outcomes and participants in each group.

\section{Assessment of Methodological Quality}

To evaluate the methodological quality of the trials, we used the Jadad scale, a validated scale for RCTs developed by Jadad et al. ${ }^{12)}$ With a total of five points, this scale assigns a point each for randomization ( 1 point if randomization is described; additional 1 point if randomization process such as table of random numbers or computer-generated randomization is described), double-blind ( 1 point if described as double-blind; additional 1 point if masking such as identical placebo was used), and follow-up (1 point for reporting the numbers and reasons for withdrawal in each group) in the final report of a randomized controlled trial. ${ }^{12)}$ In assessing the quality, RCTs with scores of 4 or less were considered low quality, while scores of 5 were high quality.

\section{Main and Subgroup Analysis}

The main analysis examined the efficacy of vitamin C supplements on cancer incidence or mortality. We also performed subgroup meta-analyses by dose of vitamin C (<500 mg vs. $\geq 500 \mathrm{mg}$ ), supplement combination (vitamin C only vs. combination with other supplements), follow-up period ( $<7$ years vs. $\geq 7$ years), methodological quality (high quality vs. low quality), outcome (cancer incidence vs. cancer mortality), gender (male vs. female), funding source (non-pharmaceutical vs. pharmaceutical), smoking status (never vs. former vs. current), participant nationality (China vs. USA vs. France vs. UK), and type of cancer.

\section{Statistical Analyses}

Trial heterogeneity of were assessed using Higgins $\mathrm{I}^{2}$, which measures the total variation across trials for a specific percentage. $\mathrm{I}^{2}$ was calculated as follows:

$$
\mathrm{I}^{2}=100 \% \times(Q-\mathrm{df}) / Q,
$$

where $\mathrm{Q}$ stands for Cochran's heterogeneity statistic, and $\mathrm{df}$ for the degrees of freedom. Negative $\mathrm{I}^{2}$ values are set to zero so that an $\mathrm{I}^{2}$ value is always between $0 \%$ (no heterogeneity) and $100 \%$ (maximal heterogeneity). $\mathrm{I}^{2}$ values $>50 \%$ indicated substantial heterogeneity. 
Either fixed- or random-effects models served as the basis for calculation of pooled relative risk (RR) with $95 \%$ confidence intervals (CIs). Without substantial heterogeneity, the pooled RR with 95\% CIs were reported based on the fixed-effects models; in this case the summary estimates are similar for both the fixed- and random-effects models. With substantial heterogeneity, the summary estimates from the random-effects model were reported because often CIs are larger in the random-effects model than in the fixed-effects model. The Mantel-Haenszel and the DerSimonian and Laird methods were used for fixed- and random-effects models, respectively. We used Stata SE ver. 12.0 (Stata Co., College Station, TX, USA) for statistical analysis.

\section{RESULTS}

\section{Trial Selection}

As shown in Figure 1, a total of 785 articles were identified after searching three databases (PubMed, EMBASE, and the Cochrane Library). After excluding 59 duplicated articles and 666 articles that did not satisfy the selection criteria, the full texts of 60 articles were reviewed by two authors of this study. Among those, 53 articles were excluded for the following reasons: insufficient data $(n=3)$, describing only the study protocol or rationale $(n=1)$, identical population $(n=6)$, precancerous lesions as outcome measures $(n=20)$, supplements not relevant to study subject $(n=2)$, no available papers $(n=6)$, not fulfilling inclusion criteria $(n=13)$, or not an original study $(n=1)$. A total of seven trials were included in the final analysis.

\section{General Characteristics of Included Trials}

The seven trials included 62,619 participants with 31,326 and 31,293 randomized to the vitamin $\mathrm{C}$ supplementation and control groups, respectively. Among trials that reported age, the participants ranged from 35 to 80 years. One RCT that used lowdose vitamin $\mathrm{C}$ supplements in combination with other supplements showed a reduction in cancer incidence and mortality. ${ }^{13)}$ The remaining six RCTs showed no significant effect of vitamin C supplementation. ${ }^{14-19)}$

Table 1 shows the general characteristics of the seven RCTs included in the final analysis. The included trials were published from 1993 through 2009. The studies were conducted in China $(n=3)$, the US $(n=2)$, France $(n=1)$, and the UK $(n=1)$. Both the treatment and the follow-up periods ranged from 5 to 9.4 years. All trials used placebos in the control group. Five trials received funding from the pharmaceutical industry; the remaining two did not. The number of participants in each trial ranged from 391 to 20,536. Among the seven trials, two used only vitamin C supplements as intervention; the rest used vitamin C supplements in combination with other vitamin or antioxidant supplements. The daily vitamin $\mathrm{C}$ doses, either singly or in combination with other supplements, varied from 120 to $500 \mathrm{mg}$.

\section{Methodological Quality}

Table 2 shows the quality of study methodology included in the final meta-analysis. The quality scores ranged from 3 to 5 . Among

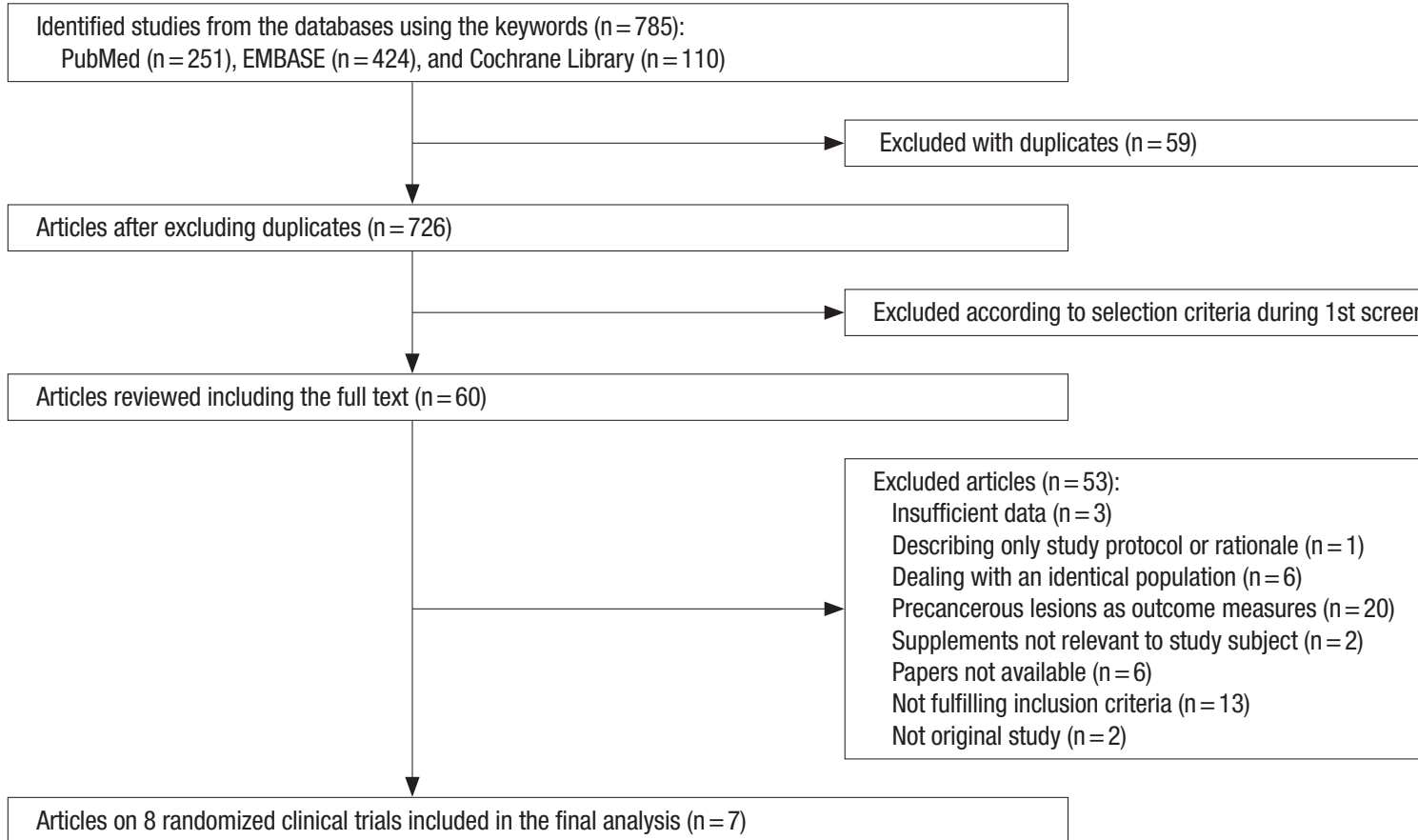

Figure 1. Flow diagram for identification of relevant studies. 


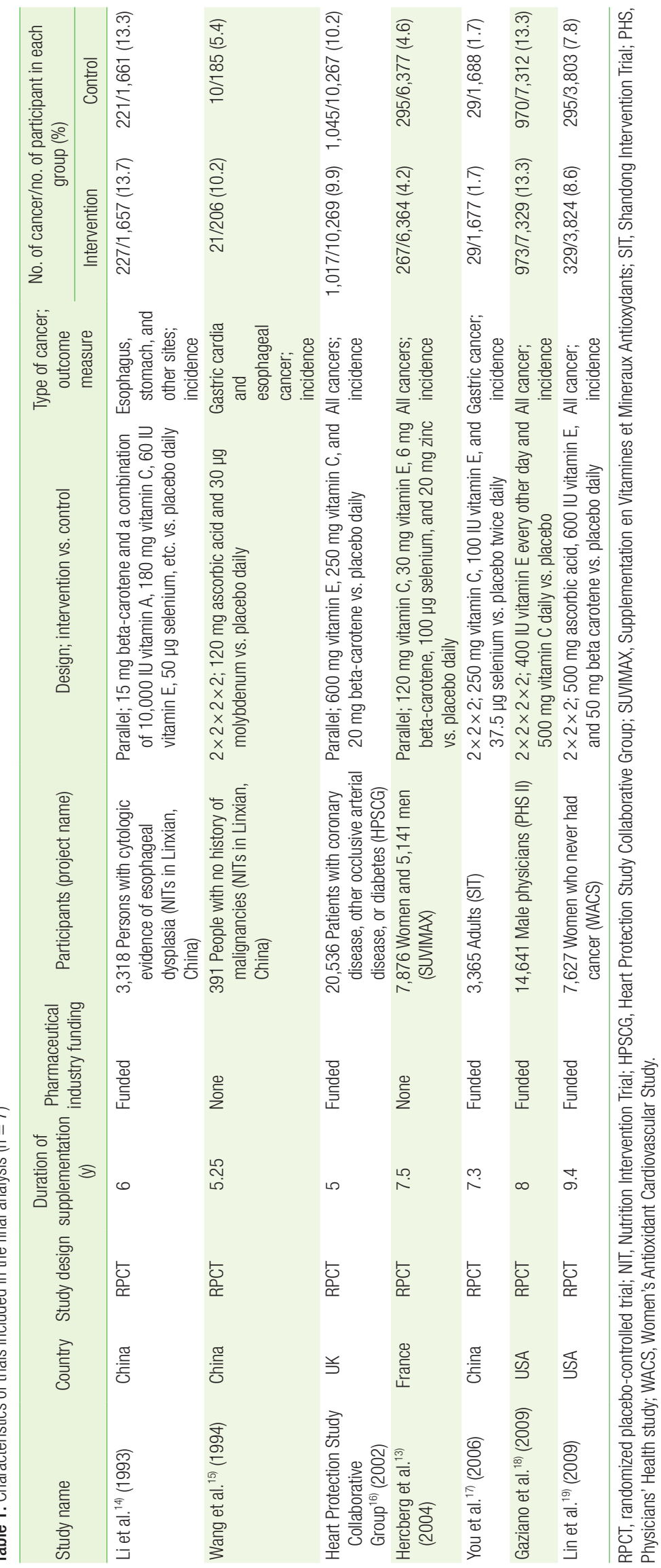

the seven trials, three trials received a score of 5 , three trials received a score of 4 , and one trial received a score of 3 .

\section{Overall Efficacy in All Seven Trials}

In a fixed-effects meta-analysis of all trials, vitamin C supplementation had no significant efficacy on cancer incidence, when compared with the control group (RR, 1.00; 95\% CIs, 0.95-1.05; $\mathrm{I}^{2}=10.3 \%$ ) (Figure 2). The Begg's funnel plot was almost symmetrical, and the Egger's test showed no bias ( $\mathrm{P}$ for bias = 0.249) (Figure 3).

\section{Subgroup Meta-Analyses}

Table 3 shows subgroup meta-analyses of the efficacy of vitamin $\mathrm{C}$ supplements on cancer according to various factors. There was no significant association between vitamin $\mathrm{C}$ supplementation and cancer in subgroup meta-analyses by vitamin $\mathrm{C}$ dose administered singly or in combination with other supplements, follow-up period, methodological quality, cancer mortality, gender, smoking status, country, and type of cancer.

\section{DISCUSSION}

In this meta-analysis of seven RCTs, we found no significant association between vitamin C supplementation and cancer risk. In addition, no efficacy of vitamin C supplements was found for the prevention of cancer in subgroup analyses according to vitamin C dose administered singly or in combination with other supplements, follow-up period, methodological quality, cancer mortality, gender, smoking status, country, and type of cancer.

Vitamin C is an electron donor that non-enzymatically stabilizes ROS by reducing them; in this process, vitamin $\mathrm{C}$ is oxidized to an ascorbyl radical. Unlike other dangerous free radicals, the ascorbyl radical is short-lived, with a half-life of $10^{-5} \mathrm{sec}$ onds, and is relatively unreactive. ${ }^{20)}$ Shortly after donating an electron, the ascorbyl radical donates another electron and is further oxidized to dehydroascorbic acid. These two oxidized forms of vitamin $C$ can be reduced back to the original state by at least three different enzyme pathways and reducing biological compounds. ${ }^{21)}$ However, not all oxidized ascorbic acid is recovered. Some dehydroascorbic acid is metabolized by hydrolysis and is lost to other biological compounds. ${ }^{22)}$ Therefore, the stability, reducibility, and reusability of oxidized 
Table 2. Methodological quality of studies included in the final analysis based on the Jadad Scale $(n=7)$

\begin{tabular}{|c|c|c|c|c|c|c|}
\hline Study & Randomization & Double-blind & $\begin{array}{l}\text { Follow-up } \\
\text { reporting }\end{array}$ & $\begin{array}{c}\text { Description of } \\
\text { randomization methods }\end{array}$ & $\begin{array}{l}\text { Using identical } \\
\text { placebo }\end{array}$ & Total score \\
\hline Li et al. ${ }^{14)}(1993)$ & 1 & 0 & 0 & 1 & 1 & 3 \\
\hline Wang et al. ${ }^{15)}(1994)$ & 1 & 0 & 1 & 1 & 1 & 4 \\
\hline Heart Protection Study Collaborative Group ${ }^{16)}(2002)$ & 1 & 0 & 1 & 1 & 1 & 4 \\
\hline Hercberg et al. ${ }^{13)}(2004)$ & 1 & 1 & 1 & 1 & 1 & 5 \\
\hline You et al. ${ }^{17)}(2006)$ & 1 & 1 & 1 & 1 & 1 & 5 \\
\hline Gaziano et al. $^{18)}(2009)$ & 1 & 1 & 1 & 1 & 1 & 5 \\
\hline Lin et al. ${ }^{19)}(2009)$ & 1 & 1 & 1 & 0 & 1 & 4 \\
\hline
\end{tabular}

\begin{tabular}{|c|c|c|}
\hline Study & Relative risk (95\% confidence interval) & Weight (\%) \\
\hline Li et al. ${ }^{14)}(1993)$ & $1.03(0.87,1.22)$ & 7.70 \\
\hline Wang et al. ${ }^{15)}(1994)$ & $1.89(0.91,3.90)$ & 0.37 \\
\hline Heart Protection Study Collaborative Group ${ }^{16)}(2002)$ & $0.97(0.90,1.06)$ & 36.44 \\
\hline Hercberg et al. ${ }^{13)}(2004)$ & $0.91(0.77,1.07)$ & 10.28 \\
\hline You et al. ${ }^{17)}(2006)$ & $0.97(0.59,1.61)$ & 1.04 \\
\hline Gaziano et al. ${ }^{18)}(2009)$ & $1.00(0.92,1.09)$ & 33.86 \\
\hline Lin et al. ${ }^{19)}(2009)$ & $1.11(0.95,1.29)$ & 10.31 \\
\hline Overall $(I-$ squared $=10.3 \%, P=0.351)$ & $1.00(0.95,1.05)$ & 100.00 \\
\hline
\end{tabular}

Figure 2. Effect of vitamin C supplement and control on cancer incidence and mortality in randomized controlled trials $(n=7)$.

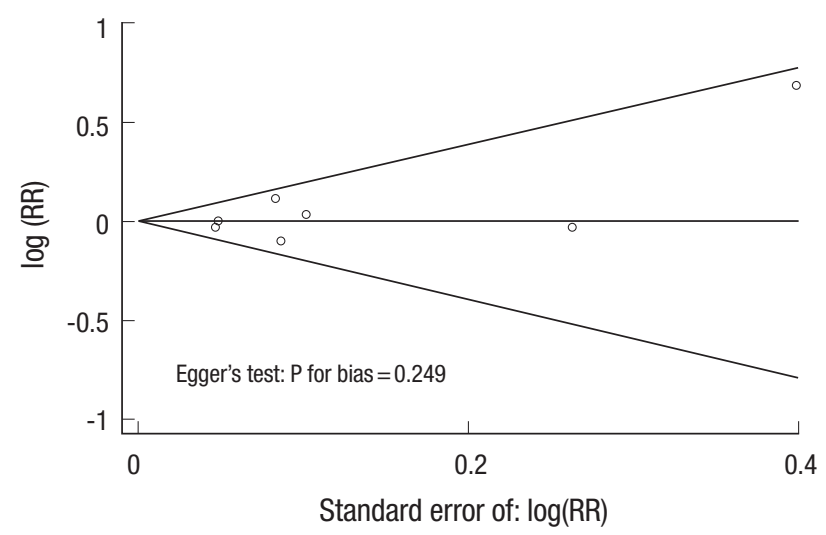

Figure 3. Begg's funnel plot and Egger's test for identifying publication bias. RR, relative risk.

ascorbic acid explain why vitamin $\mathrm{C}$ is a preferred antioxidant.

The findings of our analysis were consistent with those of previous meta-analyses of RCTs, which concluded no association between vitamin $\mathrm{C}$ and prostate, colorectal, and gastrointestinal cancers. ${ }^{9,10,23)}$ Our findings, however, were inconsistent with those of previously published preclinical in vivo or in vitro studies on this issue. ${ }^{24-26)}$ In 2005, an in vitro experiment conducted by Abdel-Latif et al. ${ }^{27)}$ suggested the efficacy of vitamin $\mathrm{C}$ supplements in facilitating apoptosis of esophageal cancer cells when used in conjunction with chemotherapy. Also, in 2010, Pollard et al. ${ }^{24)}$ showed that pharmacological doses of ascorbic acid could greatly reduce both tumor growth and cancer metastases in the prostate and lungs of rats.

This discrepancy in findings between preclinical in vivo or in vitro studies and RCTs might be due to the fact that preclinical studies may not represent biological responses in the human body ${ }^{28)}$ Anti-carcinogenic antioxidants in animals could be carcinogenic to humans. For instance, experimental studies indicated that beta-carotene reduces the risk of cancer incidence, ${ }^{29)}$ but may act as a pro-oxidant under chronic oxidative stress such as tobacco exposure in humans and lead to lung cancer. ${ }^{30,31 \text { ) }}$

In 2009, Bandera et al. ${ }^{32)}$ reported a meta-analysis of 12 casecontrol studies, indicating a strong inverse association between antioxidant vitamins and the risk of endometrial cancer. Another meta-analysis of 13 cohort studies conducted by Park et al. ${ }^{33)}$ 
Table 3. Efficacy of vitamin C supplements on cancer incidence and mortality in subgroup meta-analysis

\begin{tabular}{|c|c|c|c|c|}
\hline Variable & No. of studies & $\begin{array}{l}\text { Summary relative risk } \\
\text { (95\% confidence interval) }\end{array}$ & Heterogeneity $\left(\%, I^{2}\right)$ & Model used \\
\hline \multicolumn{5}{|l|}{ Dose of vitamin C supplements } \\
\hline$<500 \mathrm{mg}$ & 5 & $0.98(0.91-1.05)$ & 7.3 & Fixed-effects \\
\hline$\geq 500 \mathrm{mg}$ & 2 & $1.03(0.95-1.10)$ & 27.3 & Fixed-effects \\
\hline \multicolumn{5}{|l|}{ Supplement combination } \\
\hline Vitamin C only & 2 & $1.03(0.95-1.10)$ & 27.3 & Fixed-effects \\
\hline Combination with other supplements & 5 & $0.98(0.91-1.04)$ & 7.5 & Fixed-effects \\
\hline \multicolumn{5}{|l|}{ Follow-up period (y) } \\
\hline$<7$ & 3 & $0.99(0.92-1.07)$ & 41.1 & Fixed-effects \\
\hline$\geq 7$ & 4 & $1.00(0.94-1.07)$ & 6.7 & Fixed-effects \\
\hline \multicolumn{5}{|l|}{ Methodological quality } \\
\hline High quality (score =5) & 3 & $0.98(0.91-1.05)$ & 0 & Fixed-effects \\
\hline Low quality (score $\leq 4$ ) & 4 & $1.02(0.95-1.10)$ & 36.0 & Fixed-effects \\
\hline \multicolumn{5}{|l|}{ Outcome } \\
\hline Cancer incidence & 7 & $1.00(0.95-1.05)$ & 10.3 & Fixed-effects \\
\hline Cancer mortality & 4 & $1.06(0.96-1.17)$ & 0 & Fixed-effects \\
\hline \multicolumn{5}{|l|}{ Funding source } \\
\hline Non-pharmaceutical & 2 & $1.20(0.60-2.40)$ & 73.1 & Random-effects \\
\hline Pharmaceutical & 5 & $1.01(0.96-1.07)$ & 0 & Fixed-effects \\
\hline \multicolumn{5}{|l|}{ Gender } \\
\hline Male & 2 & $0.87(0.62-1.20)$ & 82.2 & Random-effects \\
\hline Female & 2 & $1.09(0.96-1.23)$ & 0 & Fixed-effects \\
\hline \multicolumn{5}{|l|}{ Smoking } \\
\hline Never & 2 & $1.06(0.95-1.18)$ & 0 & Fixed-effects \\
\hline Former & 2 & $1.00(0.90-1.11)$ & 39.3 & Fixed-effects \\
\hline Current & 2 & $0.97(0.64-1.47)$ & 59.8 & Random-effects \\
\hline \multicolumn{5}{|l|}{ Country } \\
\hline China & 3 & $1.06(0.90-1.24)$ & 0 & Fixed-effects \\
\hline USA & 2 & $1.03(0.95-1.10)$ & 27.3 & Fixed-effects \\
\hline France & 1 & $0.91(0.77-1.07)$ & NA & NA \\
\hline UK & 1 & $0.98(0.89-1.08)$ & NA & NA \\
\hline \multicolumn{5}{|l|}{ Type of cancer } \\
\hline Respiratory & 4 & $1.06(0.73-1.53)$ & 68.4 & Random-effects \\
\hline Haematological & 4 & $1.06(0.87-1.28)$ & 0 & Fixed-effects \\
\hline Skin & 3 & $0.95(0.81-1.11)$ & 0 & Fixed-effects \\
\hline Stomach & 3 & $1.19(0.93-1.51)$ & 25.2 & Fixed-effects \\
\hline Esophageal & 2 & $0.98(0.78-1.24)$ & 0 & Fixed-effects \\
\hline Colorectal & 2 & $0.84(0.64-1.10)$ & 0 & Fixed-effects \\
\hline Breast & 2 & $1.04(0.87-1.25)$ & 0 & Fixed-effects \\
\hline Pancreas & 2 & $1.37(0.58-3.20)$ & 60.5 & Random-effects \\
\hline Genitourinary & 2 & $0.88(0.76-1.02)$ & 0 & Fixed-effects \\
\hline Prostate & 1 & $1.01(0.90-1.14)$ & NA & NA \\
\hline Bladder & 1 & $0.84(0.53-1.34)$ & NA & NA \\
\hline Uterine & 1 & $0.85(0.49-1.48)$ & NA & NA \\
\hline Ovary & 1 & $0.83(0.36-1.93)$ & NA & NA \\
\hline Thyroid & 1 & $1.37(0.63-2.97)$ & NA & NA \\
\hline Oral & 1 & $0.50(0.13-2.00)$ & NA & NA \\
\hline Central nervous system & 1 & $1.38(0.55-3.42)$ & NA & NA \\
\hline
\end{tabular}

NA, not applicable.

showed a slight inverse association between vitamin C supplementation and the risk of colon cancer.

A similar discrepancy in findings between observational epidemiologic studies and RCTs might be explained by recall and selection biases common in retrospective studies such as casecontrol studies. As for recall bias, recollection of diet may differ between cancer patients and healthy controls; cancer patients are prone to report an unhealthy diet, while healthy controls report otherwise. ${ }^{34,35)}$
In evaluating the association between use of antioxidant supplements and risk of cancer, cohort studies are less biased than case-control studies, but causation cannot be sufficiently supported ${ }^{36,37)}$ The diet assessment tools used in cohort studies might not precisely evaluate participants' long-term vitamin C consumption. In addition, use of vitamin C supplements in trials differs from the intake of fruit and vegetables rich in vitamin $\mathrm{C}$ in cohort studies, which contain other vitamins and micronutrients in addition to vitamin $\mathrm{C}$. That is, vitamin $\mathrm{C}$ might have 
beneficial effects when administered in combination with other nutrients.

It is noteworthy that our findings are similar to those of the previously published meta-analysis of RCTs on the association between antioxidant supplementation and cancer and mortality. In 2007, Bjelakovic et al. ${ }^{38)}$ reported the results of meta-analysis of 47 high-quality trials involving 180,938 participants. Their findings showed that vitamin A, vitamin E, or beta-carotene supplementation increased mortality while vitamin $\mathrm{C}$ and selenium were not significantly associated with mortality. ${ }^{38)}$ The authors proposed that removing free radicals through antioxidant supplementation might impede some major defensive mechanisms such as apoptosis, phagocytosis, and detoxification, thus increasing mortality. Similarly, in 2010, Myung et al. ${ }^{39}$ ) reported that antioxidant supplements showed no significant effect on primary and secondary cancer prevention. Furthermore, in subgroup meta-analysis of four RCTs by type of cancer revealed increased risk of bladder cancer. ${ }^{39)}$

Regarding the efficacy of high-dose vitamin C therapy, the different findings between Cameron and Pauling ${ }^{5,6)}$ and Creagan et al. ${ }^{7)}$ and Moertel et al. ${ }^{8}$ have marked an ongoing controversy. There are two important differences between the two trials. First, Cameron and Pauling ${ }^{5,6)}$ used both intravenous and oral administrations of vitamin $\mathrm{C}$, while Creagan et al. ${ }^{7)}$ and Moertel et al. ${ }^{8)}$ only used oral administration. In general, the concentration of ascorbic acid was much higher when administered intravenously than orally. Furthermore, higher concentrations of vitamin $\mathrm{C}$ have been found to accumulate in tumors compared to normal tissues. ${ }^{40-42)}$ Likewise, laboratory data suggested the toxicity of high-dose vitamin C in cancer cell lines. ${ }^{43-45)}$ Chen et al. ${ }^{46)}$ suggested that elevated concentrations of ascorbic acid might increase formation of hydrogen peroxide $\left(\mathrm{H}_{2} \mathrm{O}_{2}\right)$, which may be toxic to tumor cells. This suggests a possible explanation for why Cameron and Pauling ${ }^{5,6)}$ found high-dose vitamin C supplementation to be therapeutic, while Moertel et $\mathrm{al}^{8)}$ did not. The other difference is that the studies by Cameron and Pauling, ${ }^{5,6)}$ were not RCTs, while those by Creagan and Moertel were RCTs. Cameron and Pauling ${ }^{5,6)}$ used matched controls without randomization. Additional large randomized, double-blind, placebo-controlled trials are necessary to investigate the effects of oral or intravenous administration of high-dose vitamin $\mathrm{C}$ therapy on cancer risk.

Our study has several limitations. First, we were unable to investigate the beneficial effects of vitamin $\mathrm{C}$ supplements on cancer in patients with vitamin $\mathrm{C}$ deficiency because few RCTs included these populations. Further trials are needed to explore this association. Second, our findings should not be directly translated to the effects of fruit and vegetables rich in vitamin $C$. Last, the participants included in our meta-analysis were mostly 50-60 years of age. Thus, our findings cannot be generalized to younger populations. Further RCTs in younger participants are therefore necessary.

In summary, our meta-analyses of RCTs showed no efficacy of vitamin C supplementation for prevention of cancer. Further large-scale, randomized controlled trials are necessary to confirm our findings.

\section{CONFLICT OF INTEREST}

No potential conflict of interest relevant to this article was reported.

\section{REFERENCES}

1. Dizdaroglu M, Jaruga P. Mechanisms of free radical-induced damage to DNA. Free Radic Res 2012;46:382-419.

2. Pitocco D, Zaccardi F, Di Stasio E, Romitelli F, Santini SA, Zuppi C, et al. Oxidative stress, nitric oxide, and diabetes. Rev Diabet Stud 2010; 7:15-25.

3. Cameron E, Pauling L. The orthomolecular treatment of cancer. I. The role of ascorbic acid in host resistance. Chem Biol Interact 1974;9:27383.

4. Cameron E, Campbell A. The orthomolecular treatment of cancer. II. Clinical trial of high-dose ascorbic acid supplements in advanced human cancer. Chem Biol Interact 1974;9:285-315.

5. Cameron E, Pauling L. Supplemental ascorbate in the supportive treatment of cancer: prolongation of survival times in terminal human cancer. Proc Natl Acad Sci U S A 1976;73:3685-9.

6. Cameron E, Pauling L. Supplemental ascorbate in the supportive treatment of cancer: reevaluation of prolongation of survival times in terminal human cancer. Proc Natl Acad Sci U S A 1978;75:4538-42.

7. Creagan ET, Moertel CG, O'Fallon JR, Schutt AJ, O'Connell MJ, Rubin J, et al. Failure of high-dose vitamin C (ascorbic acid) therapy to benefit patients with advanced cancer: a controlled trial. N Engl J Med 1979; 301:687-90.

8. Moertel CG, Fleming TR, Creagan ET, Rubin J, O'Connell MJ, Ames MM. High-dose vitamin C versus placebo in the treatment of patients with advanced cancer who have had no prior chemotherapy: a randomized double-blind comparison. N Engl J Med 1985;312:137-41.

9. Coulter ID, Hardy ML, Morton SC, Hilton LG, Tu W, Valentine D, et al. Antioxidants vitamin $\mathrm{C}$ and vitamin e for the prevention and treatment of cancer. J Gen Intern Med 2006;21:735-44.

10. Bjelakovic G, Nikolova D, Simonetti RG, Gluud C. Systematic review: primary and secondary prevention of gastrointestinal cancers with antioxidant supplements. Aliment Pharmacol Ther 2008;28:689-703.

11. Jiang L, Yang KH, Tian JH, Guan QL, Yao N, Cao N, et al. Efficacy of antioxidant vitamins and selenium supplement in prostate cancer prevention: a meta-analysis of randomized controlled trials. Nutr Cancer 2010;62:719-27.

12. Jadad AR, Moore RA, Carroll D, Jenkinson C, Reynolds DJ, Gavaghan DJ, et al. Assessing the quality of reports of randomized clinical trials: is blinding necessary? Control Clin Trials 1996;17:1-12.

13. Hercberg S, Galan P, Preziosi P, Bertrais S, Mennen L, Malvy D, et al. The SU.VI.MAX Study: a randomized, placebo-controlled trial of the health effects of antioxidant vitamins and minerals. Arch Intern Med 
2004;164:2335-42.

14. Li JY, Taylor PR, Li B, Dawsey S, Wang GQ, Ershow AG, et al. Nutrition intervention trials in Linxian, China: multiple vitamin/mineral supplementation, cancer incidence, and disease-specific mortality among adults with esophageal dysplasia. J Natl Cancer Inst 1993;85:1492-8.

15. Wang GQ, Dawsey SM, Li JY, Taylor PR, Li B, Blot WJ, et al. Effects of vitamin/mineral supplementation on the prevalence of histological dysplasia and early cancer of the esophagus and stomach: results from the General Population Trial in Linxian, China. Cancer Epidemiol Biomarkers Prev 1994;3:161-6.

16. Heart Protection Study Collaborative Group. MRC/BHF Heart Protection Study of antioxidant vitamin supplementation in 20,536 high-risk individuals: a randomized placebo-controlled trial. Lancet 2002;360: 23-33.

17. You WC, Brown LM, Zhang L, Li JY, Jin ML, Chang YS, et al. Randomized double-blind factorial trial of three treatments to reduce the prevalence of precancerous gastric lesions. J Natl Cancer Inst 2006;98:97483.

18. Gaziano JM, Glynn RJ, Christen WG, Kurth T, Belanger C, MacFadyen J, et al. Vitamins $\mathrm{E}$ and $\mathrm{C}$ in the prevention of prostate and total cancer in men: the Physicians' Health Study II randomized controlled trial. JAMA 2009;301:52-62.

19. Lin J, Cook NR, Albert C, Zaharris E, Gaziano JM, Van Denburgh M, et al. Vitamins $\mathrm{C}$ and $\mathrm{E}$ and beta carotene supplementation and cancer risk: a randomized controlled trial. J Natl Cancer Inst 2009;101:14-23.

20. Buettner GR, Moseley PL. EPR spin trapping of free radicals produced by bleomycin and ascorbate. Free Radic Res Commun 1993;19 Suppl 1:S89-93.

21. Bielski BH, Richter HW, Chan PC. Some properties of the ascorbate free radical. Ann N Y Acad Sci 1975;258:231-7.

22. Lewin S. Vitamin C: its molecular biology and medical potential. London: Academic Press; 1976.

23. Papaioannou D, Cooper KL, Carroll C, Hind D, Squires H, Tappenden P, et al. Antioxidants in the chemoprevention of colorectal cancer and colorectal adenomas in the general population: a systematic review and meta-analysis. Colorectal Dis 2011;13:1085-99.

24. Pollard HB, Levine MA, Eidelman O, Pollard M. Pharmacological ascorbic acid suppresses syngeneic tumor growth and metastases in hormone-refractory prostate cancer. In Vivo 2010;24:249-55.

25. Takemura Y, Satoh M, Satoh K, Hamada H, Sekido Y, Kubota S. High dose of ascorbic acid induces cell death in mesothelioma cells. Biochem Biophys Res Commun 2010;394:249-53.

26. Du J, Martin SM, Levine M, Wagner BA, Buettner GR, Wang SH, et al. Mechanisms of ascorbate-induced cytotoxicity in pancreatic cancer. Clin Cancer Res 2010;16:509-20.

27. Abdel-Latif MM, Raouf AA, Sabra K, Kelleher D, Reynolds JV. Vitamin $\mathrm{C}$ enhances chemosensitization of esophageal cancer cells in vitro. J Chemother 2005;17:539-49.

28. Farbstein D, Kozak-Blickstein A, Levy AP. Antioxidant vitamins and their use in preventing cardiovascular disease. Molecules 2010;15:8098110.

29. De Flora S, Bagnasco M, Vainio H. Modulation of genotoxic and related effects by carotenoids and vitamin A in experimental models: mechanistic issues. Mutagenesis 1999;14:153-72.
30. Cui Y, Lu Z, Bai L, Shi Z, Zhao WE, Zhao B. Beta-Carotene induces apoptosis and up-regulates peroxisome proliferator-activated receptor gamma expression and reactive oxygen species production in MCF-7 cancer cells. Eur J Cancer 2007;43:2590-601.

31. Mayne ST, Handelman GJ, Beecher G. Beta-Carotene and lung cancer promotion in heavy smokers: a plausible relationship? J Natl Cancer Inst 1996;88:1513-5.

32. Bandera EV, Gifkins DM, Moore DF, McCullough ML, Kushi LH. Antioxidant vitamins and the risk of endometrial cancer: a dose-response meta-analysis. Cancer Causes Control 2009;20:699-711.

33. Park Y, Spiegelman D, Hunter DJ, Albanes D, Bergkvist L, Buring JE, et al. Intakes of vitamins A, C, and E and use of multiple vitamin supplements and risk of colon cancer: a pooled analysis of prospective cohort studies. Cancer Causes Control 2010;21:1745-57.

34. Key TJ, Allen NE, Spencer EA, Travis RC. The effect of diet on risk of cancer. Lancet 2002;360:861-8

35. Giovannucci E, Stampfer MJ, Colditz GA, Manson JE, Rosner BA, Longnecker $\mathrm{M}$, et al. A comparison of prospective and retrospective assessments of diet in the study of breast cancer. Am J Epidemiol 1993;137: 502-11.

36. Hercberg S, Galan P, Preziosi P, Alfarez MJ, Vazquez C. The potential role of antioxidant vitamins in preventing cardiovascular diseases and cancers. Nutrition 1998;14:513-20.

37. Biasco G, Paganelli GM. European trials on dietary supplementation for cancer prevention. Ann NY Acad Sci 1999;889:152-6.

38. Bjelakovic G, Nikolova D, Gluud LL, Simonetti RG, Gluud C. Mortality in randomized trials of antioxidant supplements for primary and secondary prevention: systematic review and meta-analysis. JAMA 2007; 297:842-57.

39. Myung SK, Kim Y, Ju W, Choi HJ, Bae WK. Effects of antioxidant supplements on cancer prevention: meta-analysis of randomized controlled trials. Ann Oncol 2010;21:166-79.

40. Honegger CG, Torhorst J, Langemann H, Kabiersch A, Krenger W. Quantitative determination of water-soluble scavengers in neoplastic and non-neoplastic human breast tissue. Int J Cancer 1988;41:690-4.

41. Langemann H, Torhorst J, Kabiersch A, Krenger W, Honegger CG. Quantitative determination of water- and lipid-soluble antioxidants in neoplastic and non-neoplastic human breast tissue. Int J Cancer 1989;43: 1169-73.

42. Agus DB, Vera JC, Golde DW. Stromal cell oxidation: a mechanism by which tumors obtain vitamin C. Cancer Res 1999;59:4555-8.

43. Benade L, Howard T, Burk D. Synergistic killing of Ehrlich ascites carcinoma cells by ascorbate and 3-amino-1,2,4,-triazole. Oncology 1969; 23:33-43.

44. Bram S, Froussard P, Guichard M, Jasmin C, Augery Y, Sinoussi-Barre F, et al. Vitamin C preferential toxicity for malignant melanoma cells. Nature 1980;284:629-31.

45. Leung PY, Miyashita K, Young M, Tsao CS. Cytotoxic effect of ascorbate and its derivatives on cultured malignant and nonmalignant cell lines. Anticancer Res 1993;13:475-80.

46. Chen Q, Espey MG, Krishna MC, Mitchell JB, Corpe CP, Buettner GR, et al. Pharmacologic ascorbic acid concentrations selectively kill cancer cells: action as a pro-drug to deliver hydrogen peroxide to tissues. Proc Natl Acad Sci U S A 2005;102:13604-9. 